\title{
Testing concrete samples prepared with different types of industrial wastes
}

\author{
Jozef Junak, Nadezda Stevulova, Martina Draganovska \\ Technical University of Kosice, Civil engineering faculty, Institute of Environmental engineering, Department of Material engineering, \\ Vysokoslkolska 4, Kosice, SK-042 00, Slovakia
}

\begin{abstract}
This paper analyses the generation and re-use of different types of industrial wastes. From examined wastes, blast-furnace slag and washed recycled concrete were prepared our tested concrete samples with dimension $150 \times 150 \times 150 \mathrm{~mm}$. In these samples were fraction 0 $4 \mathrm{~mm}$ replacement by blast-furnace slag with a range of variation from 0 to $100 \%$. Fraction $4-8 \mathrm{~mm}$ and $8-16$ mm were replacement by aggregate prepared from washed recycled concrete parts with a range of variation from 0 to $100 \%$ in both fractions. Concrete samples contained aggregate prepared form recycled concrete and blast-furnace slag, are tested after 14 and 28 days of hardening. From the obtained results follows that washed recycled concrete and blast-furnace slag can be successfully used as a natural aggregate replacement in concrete production and has not negative effects on the properties of hardened concrete. Before mass using of these selected wastes, some important properties (durability and corrosion) of recycled concrete and blast-furnace slag concrete are necessary to investigate.
\end{abstract}

Keywords: blast-furnace slag, aggregate from recycled concrete, compressive strengths, concrete.

\section{Introduction}

Many innovative businesses have successfully introduced "green" products in recent years. While many of these products have saved money, they have also reduced impacts on human health and the environment by using recycled or recyclable material, reducing their energy usage or eliminating the use of toxic chemicals during their manufacture.

The world's yearly cement production of 1.6 billion tons accounts for about $7 \%$ of the global loading of carbon dioxide into the atmosphere. Portland cement, the principal hydraulic cement in use today, is not only one of the most energyintensive materials of construction but also is responsible for a large amount of greenhouse gases. Producing a ton of portland cement requires about 4 GJ energy, and portland cement clinker manufacture releases approximately 1 ton of carbon dioxide into the atmosphere. Furthermore, mining large quantities of raw materials such as limestone and clay, and fuel such as coal, often results in extensive deforestation and top-soil loss. Ordinary concrete typically contains about $12 \%$ cement and $80 \%$ aggregate by mass. This means that globally, for concrete making, we are consuming sand, gravel, and crushed rock at the rate of 10 to 11 billion tons every year. The mining, processing, and transport operations involving such large quantities of aggregate consume considerable amounts of energy, and adversely affect the ecology of forested areas and riverbeds. The concrete industry also uses large amounts of fresh water; the mixing water requirement alone is approximately 1 trillion L every year. Reliable estimates aren't available, but large quantities of fresh water are being used as wash-water by the ready mixed concrete industry and for curing concrete [1].

In the world is increasing demand and interest in aggregates from non-traditional sources such as from industrial byproducts and recycled construction and demolition wastes. The American Concrete Institute (ACI) focuses on the removal and reuse of hardened concrete whereas the Department of the Environment and Water Resources in Australia and CSIRO has developed a guide on the use of recycled concrete and masonry materials. The Waste \& Resources Action Programme (WRAP) in the UK classified aggregates from primary, recycled and secondary material resources. Recycled aggregates encompass industrial by-products and reused construction products, all of which were once considered wastes and dumped in landfill. The recently introduced European Standards for aggregates do not discriminate between different sources, and are for 'aggregates from natural, recycled and manufactured materials' [2].

Classification of aggregates [2]:

Corresponding author: Jozef Junak. E-mail address: Jozef.Junak@tuke.sk

http://dx.doi.org/10.3846/enviro.2014.029

(C) 2014 The Authors. Published by VGTU Press. This is an open-access article distributed under the terms of the Creative Commons Attribution License, which permits unrestricted use, distribution, and reproduction in any medium, provided the original author and source are credited. 
1. Natural aggregate: construction aggregates produced from natural sources such as gravel and sand, and extractive products such as crushed rock,

2. Manufactured aggregate: aggregates manufactured from selected naturally occurring materials, by-products of industrial processes or a combination of these,

3. Recycled aggregate: aggregates derived from the processing of materials previously used in a product and/or in construction,

4. Reused by-product: aggregates produced from by-products of industrial processes.

Recycled concrete aggregate (RCA) is generally produced by two-stage crushing of demolished concrete, and screening and removal of contaminants such as reinforcement, paper, wood, plastics and gypsum. Concrete made with such recycled concrete aggregate is called recycled aggregate concrete (RAC). When demolished concrete is crushed, a certain amount of mortar and cement paste from the original concrete remains attached to stone particles in recycled aggregate. This attached mortar is the main reason for the lower quality of RCA compared to natural aggregate. Technology of RAC production is different from the production procedure for concrete with natural aggregate. Because of the attached mortar, recycled aggregate has significantly higher water absorption than natural aggregate. Therefore, to obtain the desired workability of RAC it is necessary to add a certain amount of water to saturate recycled aggregate before or during mixing, if no waterreducing admixture is applied. One option is to first saturate recycled aggregate to the condition - water saturated surface dry, and the other is to use dried recycled aggregate and to add the additional water quantity during mixing. The additional water quantity is calculated on the basis of recycled aggregate water absorption in prescribed time [3].

Slag is a partially vitreous by-product of the process of smelting ore, which separates the desired metal fraction from the unwanted fraction. Slag is usually a mixture of metal oxides and silicon dioxide. However, slags can contain metal sulfides and metal atoms in the elemental form. While slags are generally used to remove waste in metal smelting, they can also serve other purposes, such as assisting in the temperature control of the smelting, and minimizing any re-oxidation of the final liquid metal product before the molten metal is removed from the furnace and used to make solid metal.

Blast furnace slag is, furthermore, classified into a granulated blast furnace slag and an air-cooled blast furnace slag. Granulated blast furnace slag is produced by quenching molten furnace slag with high-pressurized water [4].

Blast furnace slag is produced in parallel with hot iron in a blast furnace. The production process of the iron is adapted to ensure that the slag has the requisite technical qualities. A technical choice is made at the start of the production process that determines the type of slag that is produced. Moreover, use of the slag is certain in a number of clearly defined end uses, and demand is high. Blast furnace slag can be used directly at the end of the production process, without further processing that is not an integral part of this production process (such as crushing to get the appropriate particle size) [5].

Experiments show [6-9], that slag can be successfully used as a natural aggregate replacement in concrete production.

The concrete slump test is an empirical test that measures the workability of fresh concrete. More specifically, it measures the consistency of the concrete in that specific batch. This test is performed to check the consistency of freshly made concrete. Consistency is a term very closely related to workability. It is a term which describes the state of fresh concrete. It refers to the ease with which the concrete flows. It is used to indicate the degree of wetness. Workability of concrete is mainly affected by consistency i.e. wetter mixes will be more workable than drier mixes, but concrete of the same consistency may vary in workability. It is also used to determine consistency between individual mixtures. The slump test is used to ensure uniformity for different mixtures of similar concrete under field conditions, and to ascertain the effects of plasticizers on their introduction.

The aim of this work is to experimentally verify the suitability of the refund fraction $0 / 4 \mathrm{~mm}$ natural aggregate by alternative raw-waste material. For this purpose, we chose the blast-furnace slag. In verifying the refund $0 / 4 \mathrm{~mm}$ fractions were followed exact recipe for the concrete.

\section{Materials and methods}

Portland cement CEM II 32.2, aggregate prepared form recycled concrete, blast-furnace slag and natural aggregate were used as raw materials in our experiment.

Used recycled concrete aggregate (Fig. 1) was created as a crushed and sorted waste from demolition building and roads. This material was obtained from recycling plant Rail and Transport Buildings, Ltd. Kosice, Slovakia. This material, fraction 4/8 and 8/16 mm was wash, and used as natural aggregate replacement in concrete mixtures.

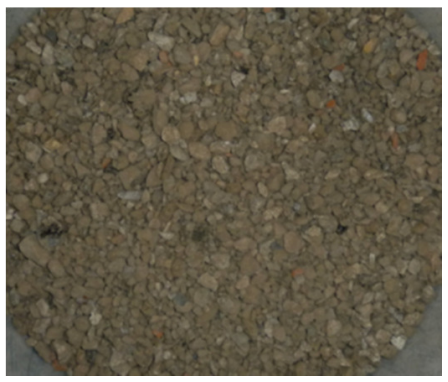

Fig. 1. Aggregate prepared from recycled concrete 
Blast-furnace slag (Fig. 2) used in our study was obtained from steel production in U.S. Steel Kosice, Slovakia. Fraction 0-4 $\mathrm{mm}$ was used as natural aggregate replacement in concrete mixtures.

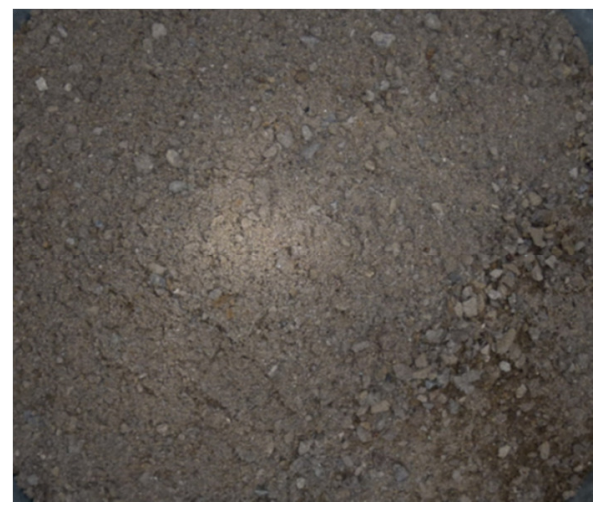

Fig. 2. Blast-furnace slag fraction $0-4 \mathrm{~mm}$

Three different fractions of natural aggregate $(0 / 4 \mathrm{~mm}, 4 / 8 \mathrm{~mm}$ and $8 / 16 \mathrm{~mm})$ from company VSH, a.s. (Turna nad Bodvou, Slovakia) was used for concrete samples preparing. Natural aggregate was evaluated according to the Slovakian standard STN EN 12620 Aggregates for concrete.

To manufacture of concrete samples was used Portland slag cement CEM II/B-S 32.5 R from company Povazska cementaren, a.a., Ladce, Slovakia, according to the Slovakian standard STN EN 197-1 Cement. Part 1: Composition, specifications and conformity criteria for common cements.

Table 1 shows proposal composition of $1 \mathrm{~m}^{3}$ concrete for strength class $\mathrm{C} 16 / 20$. As an additive to concrete samples was used plasticizer Stacheplast. It is a plasticizer based on lignin, which specifically regulates the hardening of concrete samples with a strong plasticizing effect.

Table 1. Composition of $1 \mathrm{~m}^{3}$ concrete C $16 / 20$

\begin{tabular}{ll}
\hline Composition & C 16/20 XC1, (SK)-Cl 0,4-Dmax16-S3 \\
\hline CEM II/ B-S 32.5 R [kg] & 300 \\
Water [1] & 165 \\
$0 / 4 \mathrm{~mm} \mathrm{[kg]}$ & 950 \\
$4 / 8 \mathrm{~mm}[\mathrm{~kg}]$ & 220 \\
$8 / 16 \mathrm{~mm} \mathrm{[kg]}$ & 700 \\
Plasticizer [1] & 2,15 \\
\hline
\end{tabular}

The experiment consists of two stages of production of the experimental samples, where in the first is a natural aggregate fraction $0 / 4 \mathrm{~mm}$ partially replaced by the same fraction of blast-furnace slag (10-30\%). In the second phase of the research was the natural aggregate fraction $0 / 4 \mathrm{~mm}$ again partially replaced by the $0 / 4 \mathrm{~mm}$ blast-furnace slag, but concrete mixture was carried out with $100 \%$ replacement of natural aggregate fractions $4 / 8$ and $8 / 16 \mathrm{~mm}$ by same fraction of aggregate prepared from washed recycled concrete. Sample BF0 was reference sample prepared only with natural aggregate. Total percentage of individual fractions in all samples is shown in Table 2.

Table 2. Total percentage replacement of natural aggregate by aggregate prepared from washed recycled concrete in the mixture

\begin{tabular}{llllll}
\hline $\begin{array}{l}\text { Blast-furnace } \\
\text { slag } \\
{[\%]}\end{array}$ & $\begin{array}{l}\text { Natural } \\
\text { aggregate } \\
{[\%]}\end{array}$ & $\begin{array}{l}\text { Recycled } \\
\text { aggregate } \\
{[\%]}\end{array}$ & $\begin{array}{l}\text { Natural } \\
\text { aggregate } \\
{[\%]}\end{array}$ & $\begin{array}{l}\text { Recycled } \\
\text { aggregate } \\
{[\%]}\end{array}$ & $\begin{array}{l}\text { Natural } \\
\text { aggregate } \\
{[\%]}\end{array}$ \\
\hline 0 & 100 & 0 & 100 & 0 & 100 \\
10 & 90 & 0 & 100 & 0 & 100 \\
20 & 80 & 0 & 100 & 0 & 100 \\
30 & 70 & 0 & 100 & 0 & 100 \\
0 & 100 & 100 & 0 & 100 & 0 \\
10 & 90 & 100 & 0 & 100 & 0 \\
30 & 80 & 100 & 0 & 100 & 0 \\
\hline
\end{tabular}


Experimental mixtures were processed in the laboratory mixer with a horizontal rotary drum with a capacity of 1501. Compounding process was chosen as follows: to a mixing drum are tipped aggregate in the order of fractions $8 / 16 \mathrm{~mm}, 4 / 8$ $\mathrm{mm}, 0 / 4 \mathrm{~mm}$. After a careful mixing of the all components concrete mixture were placed into cleaned plastic forms. Thus prepared forms were then over $15 \mathrm{~s}$ compacted on a vibrating table. After filling, cubic forms were labelled and placed on a flat surface next 48 hours. After 48 hours, the cube bodies were removed from the forms and then placed in a water bath. In order to realize the experiment program was made 48 pieces of test cubes with dimensions of $150 \times 150 \times 150 \mathrm{~mm}$. Time hardening of samples contained blast-furnace slag and recycled concrete aggregate was 14 and 28 days. The actual test compressive strength of the samples was carried out on the hydraulic bench press Dr MB 300.

The most important descriptive characteristics of fresh concrete is its workability. For the purpose of this experiment was selected and performed Slump test, according to the Slovakian standard STN EN 12350-2. In the test, fresh concrete were compacted in the form of a hollow truncated cone. Test is to determine the suitability of the composition of the concrete mixture for transport, shaping and compacting, or it checked by observing the values of workability of fresh concrete. The measured values of slump test of fresh concrete by this method are given in Table 3 . As is evident, in the investigated samples was achieved slump grade S3.

Table 3. The measured values of fresh concrete slump test

\begin{tabular}{llll}
\hline Sample & Water/cement ratio & Slump $[\mathrm{mm}]$ & Slump grade \\
\hline BF0 & 0.6 & 150 & $\mathrm{~S} 3$ \\
BF1 & 0.64 & 120 & $\mathrm{~S} 3$ \\
BF2 & 0.64 & 150 & $\mathrm{~S} 3$ \\
BF3 & 0.64 & 130 & $\mathrm{~S} 3$ \\
BF4 & 0.64 & 145 & $\mathrm{~S} 3$ \\
BF5 & 0.64 & 160 & $\mathrm{~S} 4$ \\
BF6 & 0.65 & 150 & $\mathrm{~S} 3$ \\
BF7 & 0.69 & 140 & $\mathrm{~S} 3$ \\
\hline
\end{tabular}

\section{Results and discussion}

In Table 4 are shown the results of each measured forces and compressive strength of all experimental samples after 14 and 28 days of hardening.

Table 4. The results of each measured forces and compressive strength of all experimental samples after 14 and 28 days of hardening

\begin{tabular}{lllll}
\hline \multirow{3}{*}{ Sample } & \multicolumn{3}{l}{ Compressive } \\
\cline { 2 - 5 } & Force & \multicolumn{3}{l}{ Strength } \\
\cline { 2 - 5 } & 14 days & 28 days & 14 days & 28 days \\
\hline BF0 & 596.7 & 715.4 & 26.8 & 32.3 \\
BF1 & 500.0 & 636.7 & 22.5 & 28.5 \\
BF2 & 566.7 & 725.0 & 25.2 & 32.3 \\
BF3 & 465.0 & 610.0 & 21.0 & 27.3 \\
BF4 & 276.7 & 338.4 & 12.3 & 15.1 \\
BF5 & 315.0 & 391.7 & 13.9 & 17.4 \\
BF6 & 281.0 & 340.0 & 12.5 & 15.1 \\
BF7 & 261.4 & 331.7 & 11.7 & 14.8 \\
\hline
\end{tabular}

None of the samples where was used aggregate prepared form recycled concrete as a complete replacement of natural aggregates fraction $4 / 8$ and $8 / 16 \mathrm{~mm}$, has not completed a standard value of $20 \mathrm{MPa}$. The probable cause of these results may be, for example high water/cement ratio. Slovak standard requirements for compressive strength after 28 days of hardening, $20 \mathrm{MPa}$ met only half of the samples.

As is evident from Figure 3, Slovakia standards compressive strength after 14 and 28 days of hardening, reached samples where only the fraction $0 / 4 \mathrm{~mm}$ of natural aggregate were replaced with blast furnace slag. The highest value of compressive strength after 28 days of hardening (32.3 MPa) reached sample BF2, which contained blast furnace slag (20\% of fraction $0 / 4 \mathrm{~mm}$ ) and natural aggregate $(80 \%$ of fraction $0 / 4 \mathrm{~mm})$. Compressive strength of sample BF2 is the same kind of reached a comparative sample BF0. This sample also has the maximum strength after 14 days of hardening (25.2 MPa). Lowest value of compressive strength after 14 and 28 days of hardening reached a sample BF7, which contained $30 \%$ blastfurnace slag fraction $0-4 \mathrm{~mm}$, and 100\% aggregate prepared from recycled concrete fraction 4-8 and 8-16 mm. 


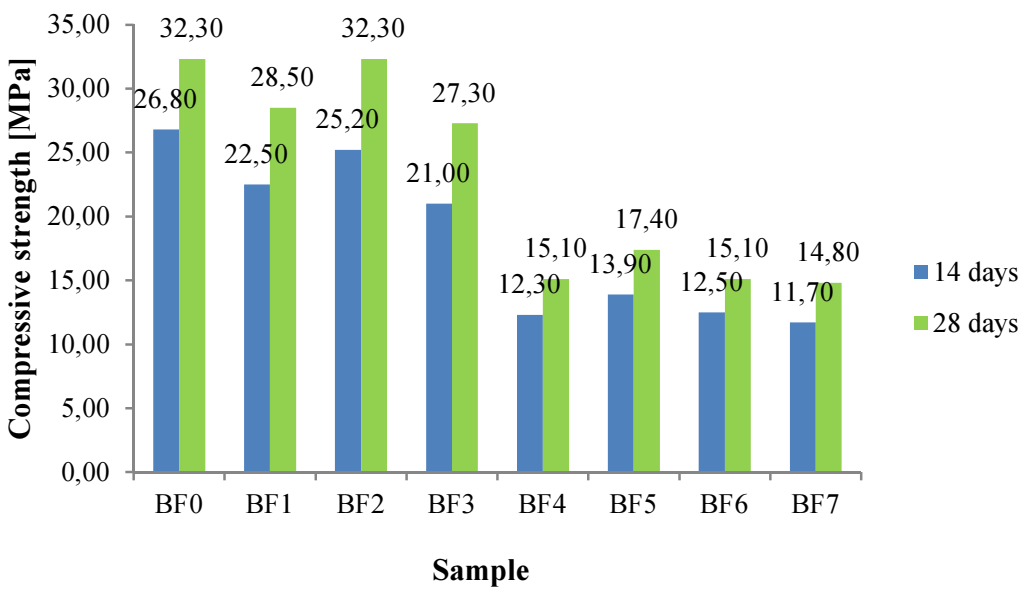

Fig. 3. The average compressive strength of experimental samples after 14 and 28 days of hardening

\section{Conclusion}

The aim of this work was to analyze and experimentally verify the possibility of replacing natural aggregate fraction $0 / 4$ $\mathrm{mm}$ in concrete strength class C 16/20 by alternative raw materials. This paper presents the results obtained from research utilization of blast furnace slag as a partial replacement of natural aggregate fraction $0 / 4 \mathrm{~mm}$ in concrete, as well as full compensation for fractions $4 / 8$ and $8 / 16 \mathrm{~mm}$ of natural aggregate by aggregate prepared from recycled concrete in combination with a partial replacement of the fine fraction $0-4 \mathrm{~mm}$ by blast-furnace slag.

The highest value of compressive strength after 28 days of hardening (32.3 MPa) reached sample, which contained blast furnace slag $(20 \%$ of fraction $0 / 4 \mathrm{~mm})$ and natural aggregate $(80 \%$ of fraction $0 / 4 \mathrm{~mm})$. Compressive strength of this sample is the same kind of reached a comparative sample. This sample also has the maximum strength after 14 days of hardening $(25.2 \mathrm{MPa})$.

Lowest value of compressive strength after 14 and 28 days of hardening reached a sample, which contained $30 \%$ blastfurnace slag fraction $0-4 \mathrm{~mm}$, and 100\% aggregate prepared from recycled concrete fraction 4-8 and 8-16 mm.

None of the samples where was used aggregate prepared form recycled concrete as a complete replacement of natural aggregates fraction $4 / 8$ and $8 / 16 \mathrm{~mm}$, has not reached a standard value of $20 \mathrm{MPa}$. The probable cause of these results may be, for example high water/cement ratio.

\section{Acknowledgements}

This research has been carried out within the Grant No. 1/0767/13 of the Slovak Grant Agency for Science.

\section{References}

[1] Metha, K. 2001. Reducing the environmental impact of concrete, Concrete Internationa, October 2001.

[2] Cement Concrete \& Aggregates Australia [online]. 2008. Use of Recycled Aggregates in Construction. Avaible from internet: http://www.concrete.net.au/publications/pdf/RecycledAggregates.pdf2

[3] Malesev, M.; Radonjanin, V.; Marinkovic, S. 2010. Recycled concrete as aggregate for structural concrete production, Sustainability (2): 1204-1225.

[4] Matsuda. H.; Shinozaki, H.; Ishikura, R.; Kitayama, N. 2008. Application of granulated furnace slag to the earthquake resistant earth structure as a geo-material, in Proc. of the 14th World conference on Earthquake Engineering, Bejing, China, 2008, 1-8.

[5] Environment agency [online]. 2007. Blast furnace slag (BFS). A technical report on the manufacturing of blast furnace slag and material status in the UK. Oxon: The Old academy. Avaible from internet:

http://www.handapp.co.uk/web/BF\%20Slag\%20\%20a\%20technical\%20report\%20on\%20manufacturing\%20of\%20BF\%20Slag\%20\&\%20material\%2 0status\%20in\%20UK.pdf

[6] Václavík, V.; Dirner, V.; Dvorský, T.; Daxner, J. 2012. Use of blast furnace slag, Metalurgija 51(4): 461-464.

[7] Ondova, M.; Stevulova, N. 2012. Benefits of Fly Ash Utilization in Concrete Road Cover, Theoretical Foundations of Chemical Engineering (46): 713-718. http://dx.doi.org/10.1134/S0040579512060176

[8] Junak, J.; Stevulova, N.; Ondova, M. 2013. New aproach to natural aggregate replacement by industrial wastes in civil engineering industry, in Proc of the 13th International Multidisciplinary Scientific Geoconference : Energy and clean technologies, Albena, Bulgaria, Sofia: STEF92 Technology Ltd., 393-399.

[9] Junak, J.; Stevulova, N. 2013. Natural aggregate replacement by recycled materials in concrete production, Visnik Nacionalnogo universitetu Lvivska politechnika : teorija i praktika budivnictva (756): 63-68 